\title{
Trends in publication on evidence-based antioxidative herbal medicines in management of diabetic nephropathy
}

\author{
Ozra Tabatabaei-Malazy ${ }^{1,2}$, Rasha Atlasi ${ }^{3}$, Bagher Larijani ${ }^{2^{*}+}$ and Mohammad Abdollahi $i^{2,4^{*}+}$
}

\begin{abstract}
Background: Recently, popularity and use of herbal medicine in treatment of diabetes have been increased. Since, oxidative stress is known as the main underlying pathophysiology of diabetes and its complications, the purpose of this bibliometric study is to assess the global scientific production analysis and developing its trend in field of antioxidative hypoglycemic herbal medicines and diabetic nephropathy focusing on the scientific publication numbers, citations, geographical distribution in the world and determining the main journal (source) in the field.
\end{abstract}

Methods: Our search terms were "diabetes", "renal", "nephropathy", "herb", "Chinese medicine", "traditional medicine", and "antioxidant" from Scopus database until January 2015 and analysis of the distribution of words in the publication year, main journal (source) in the field, geographical distribution, documents' type and language, subject area, and h-index of citations were crried out. The Scopus analysis tools and VOSviewer software version 1.6.3 have been used for analysis.

Results: Within 1166 papers were published until year 2015, 78 studies were related to this topic in human. Increasing trend in number of related researches was shown. Fifty eight percent of the published papers were original articles, and the highest number was produced in 2013 with 21 documents. Top subject areas were medicine with global publication share of $71.8 \%$, and pharmacology was ranked the second (39.7\%). Iran was the first country with global publication. The total citation of the documents were 2518 times and h-index was 24 . The highest cited paper was a review article with 336 citation number, and top source was "Journal of Medicinal Plants". Both of top authors and affiliation were from Iran; "Tehran University of Medical Sciences". Also, top author in the co-authorship mapping and clustering assessment was from Iran.

Conclusions: Although, we found an ascending trend of scientific publications in field of antioxidative herbal medicine and diabetic nephropathy with a good position for Iran, the number of publications is insufficient and more researches in this topic is necessary.

Keywords: Herbal medicine, Antioxidative, Diabetic nephropathy, Scientometric analysis

\footnotetext{
* Correspondence: Larijanib@tums.ac.ir; Mohammad.Abdollahi@UToronto.Ca

${ }^{\dagger}$ Equal contributors

Endocrinology and Metabolism Research Center, Endocrinology and

Metabolism Clinical Sciences Institute, Tehran University of Medical Sciences,

Tehran, Iran

${ }^{4}$ Department of Toxicology and Pharmacology, Faculty of Pharmacy, and

Pharmaceutical Sciences Research Center, Tehran University of Medical

Sciences, Tehran, Iran

Full list of author information is available at the end of the article
} 


\section{Background}

The prevalence of Diabetes Mellitus (DM), as the most common cause of chronic kidney disease (CKD) and renal failure, is increasing worldwide. American Diabetes Association (ADA) reported 20-40\% of diabetic patients have suffered from diabetic nephropathy [1]. Therefore, CKD should be considered as one of the most common complication of diabetes, and early intervention to delay progression to diabetic nephropathy and CKD along with providing good glycemic control would be important. Although, many synthetic drugs are available in treatment of diabetic nephropathy, only a fraction of them can be used safely in these patients. In addition, due to undesirable side effects and high cost of synthetic drugs, their dosage should be adjusted in renal failure [2]. Thus, considering alternative treatments such as herbal medicines that have been determined their safety and efficacy in the management of diabetes and its complications would be logical. Recently, popularity and use of herbal medicine among different age groups in both developing and developed countries for treatment of diabetes have been increased [2-4]. However, there has been no systematic analysis of scientific productions' trends in field of antioxidative hypoglycemic herbal medicines and diabetic nephropathy. The scientometric analysis has been determined as a reliable and practical method to measure, and evaluate the current scientific research directions in a specific field by focusing on numbers of published papers and their citation' numbers [5]. Considering the increasing prevalence of diabetes and its complications, there exists a need for sufficient scientific evidences obtained from scientific interactions and journals to design a suitable preventive plan $[2-4,6]$. In addition, it is more essential to pay attention to oxidative stress as the main underlying pathology of diabetes and its complications [7-10]. In the present study, we investigate a scientometric study of scientific productions in field of antioxidative herbal medicines and diabetic nephropathy focusing on the scientific publication numbers, citations, geographical distribution in the world, determining the main journal (source) in the field, and co-authorship mapping and clustering assessment.

\section{Methods}

\section{Data source}

The study is based on information from Scopus database for scientific publications and on growth data recorded in the literature. The Scopus database was known as one of the most comprehensive source of bibliographic data due to its high coverage in health and biomedicine disciplines and its reliable citations' report for academic articles. In addition, it is important its accessibility to valid different analysis tools
[11-13] that can feasible analysis of the collected data. The quality and reliability of the information gathered, in particular with regard to citation and author affiliations were considered.

\section{Search strategies}

The Scopus database was searched to compile a bibliography of all papers related on antioxidative herbal medicines in management of diabetic nephropathy which compromising ((TITLE-ABS-KEY ("Phytotherapy" OR "Naturopathic" OR "Drug*" OR "Plant"” OR "Medic*" OR "Herb" " OR "Flower") AND TITLE-ABS-KEY (("Chinese" OR “Traditional” OR "Primitive" OR "Indigenous") OR ("Folk" AND "Remed") OR "Ethnomedicine" OR ("Remedy" AND "Home") OR "Ethnopharmacology" OR "NATURAL" OR "extract*" OR "COMPONENT*") AND TITLE-ABS-KEY("DIABET" AND “TYPE2" OR "type 2" OR “TYPEII" OR “TYPE II” OR “TYPE-II” OR “T2DM” OR “T2D” OR "NIDDM") AND ALL(“Antioxidant" OR "Anti-Oxidant" OR "Anti Oxidant" OR "Antioxidative” OR "Anti-Oxidative" OR "Anti Oxidative" OR "OXIDANT" OR “OXIDANTS” OR “OXIDATIVE”)) AND ALL("kidney” OR "renal” OR "nephro" OR "protein"” OR "albumin"” OR "creatin*"). The meaning of the TITLE-ABS-KEY code combined field is searching abstracts, keywords, and article titles.

The inclusion criteria were all relevant available scientific publications in field of antioxidative hypoglycemic herbal medicine and diabetic nephropathy which conducted in human and published before January 2015.

After assessment literature in title and abstract of all papers, duplicated articles were excluded. Other exclusion criteria were studies conducted in children, adolescents, pregnant women, type 1 diabetes mellitus, or animal studies. No language limitation was considered. Finally, 78 documents were analyzed.

\section{Data analysis}

In overall, the impact factors (IF) of each journal that was used as a quantitative indicator to assess, compare, and rank of scientific publications [14], developed to faciliate comparison between citation rates of journals and evolved as a measurement of journal quality. The collected data were publication year, the main journal (source) in the field, author's name and affiliation, country distribution, document's type and language, subject area, documents' citations, $h$-Index and the $h$-graph. The $h$-Index and $h$-graph are indicators to measure of research performance quality by showing the number of citations per document [15]. The Scopus web database was used to analysis extracted data. The SPSS version 15 was used to assess correlation between number of published papers and year of publication. VOSviewer 


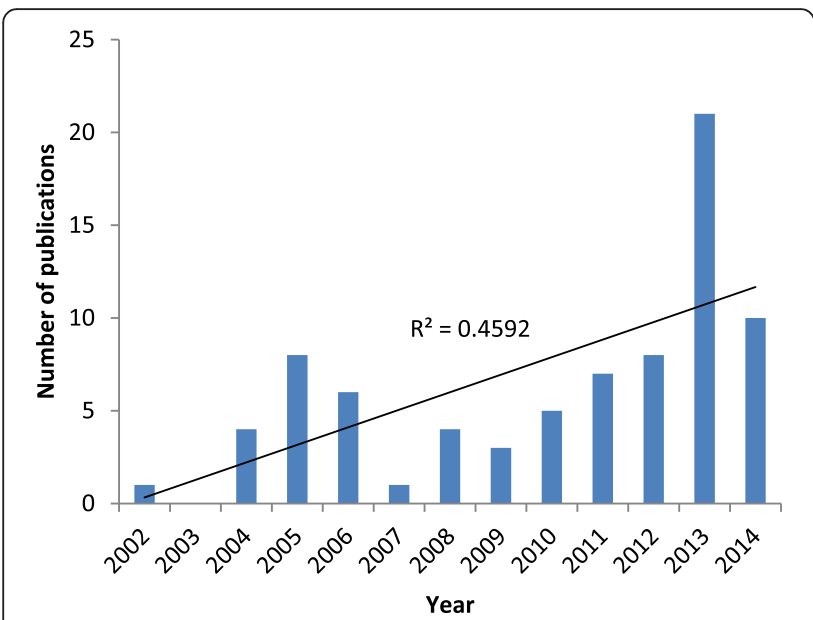

Fig. 1 Time-trend distribution of document types in antioxidative herbal medicine and diabetic nephropathy

(Visualizing Scientific Landscapes) software version 1.6.3 that is available in www.vosviewer.com has been used for co-authorship mapping and clustering assessment to provide information on scientific collaboration between co-authors in the field.

\section{Results}

\section{Time-trend in publications}

Figure 1 shows the distribution of document type identified by Scopus analyzed. It is shown three pikes in number of published articles in years 2005, 2008, and 2013 compared to previous years. We found the highest number of scientific productions in 2013 (26.9\% equivalent to 21 documents), while the lowest publication was in 2007, and 2002 (each one $1.28 \%$, equivalent to 1 document). The overall correlation reflecting the association between number of published documents and year of publication was 0.728 with $p$ value $=0.005$. The $\mathrm{R}$-squared value of 0.459 suggests a steady and significant increase since 2002 to 2015 .

\section{Type and language of documents}

Our analysis reveals among 78 documents, the majority of them (45 documents, $57.7 \%$ ) were original articles, followed by review articles (33 documents, $42.3 \%$ ).
Totally, the studied documents were published in four languages; English, Persian, Chinese, and German. Most of documents were in English language (88.46 \%).

\section{Subject area}

Top subject area was medicine with global publication share of 71.8 percent. Pharmacology ranked the second (39.7\%) and biochemistry/genetics/molecular biology (20 documents, $25.6 \%$ ) was the third rank.

\section{Geographical distribution}

In overall, in the global publication share of the top 5 countries, Iran topped the list with global publication share of 19 documents (25\%), the United States with 11 (14.47\%), China and India each one with 6 documents (7.89\%), and United Kingdom with 5 documents were 5 top countries with high number of publications.

\section{Citations' numbers}

Figure 2 shows the changes in the total number of citations in each year. A total of 1166 publications were published until year 2015 have received to total number of citations 2518 times at the time of data analysis (until July $\left.21^{\text {th }}, 2015\right)$. The average number of citation per article was 33.13.

Among articles, 64 documents (82\%) were cited at least once and 14 documents (18\%) did not have any citation at all. The highest number of citations (336 times) was happen in 2006 while there was not any citations during years 2000 and 2002.

The $h$-index for 78 analyzed documents was 24 . This means 24 documents were cited at least 24 times (Fig. 3).

In Table 1 that summarizes characteristics of the top ten highly cited articles, citation number ranged from 336 times to 79 times. Highly cited publication was a review paper entitled "Green tea and its polyphenolic catechins: medicinal uses in cancer and noncancer applications" which has been cited 336 times, followed by another review paper etitled "Curcumin: getting back to the roots", 289 times. Findings shown that highly cited original article was entitled "Beneficial effects of soy phytoestrogen intake in postmenopausal women with type 2 diabetes" which has been cited 187 times.

As shown in Table 1, of 10 highly cited articles 7 articles were review, and 3 papers were original articles. The United States was ranked at first country with 4

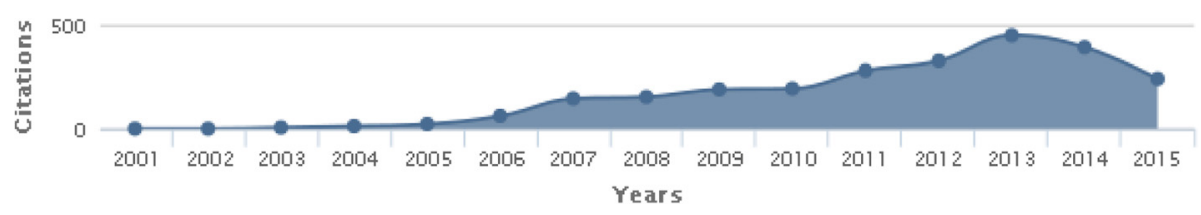

Fig. 2 Chart of citation of published documents in our study 


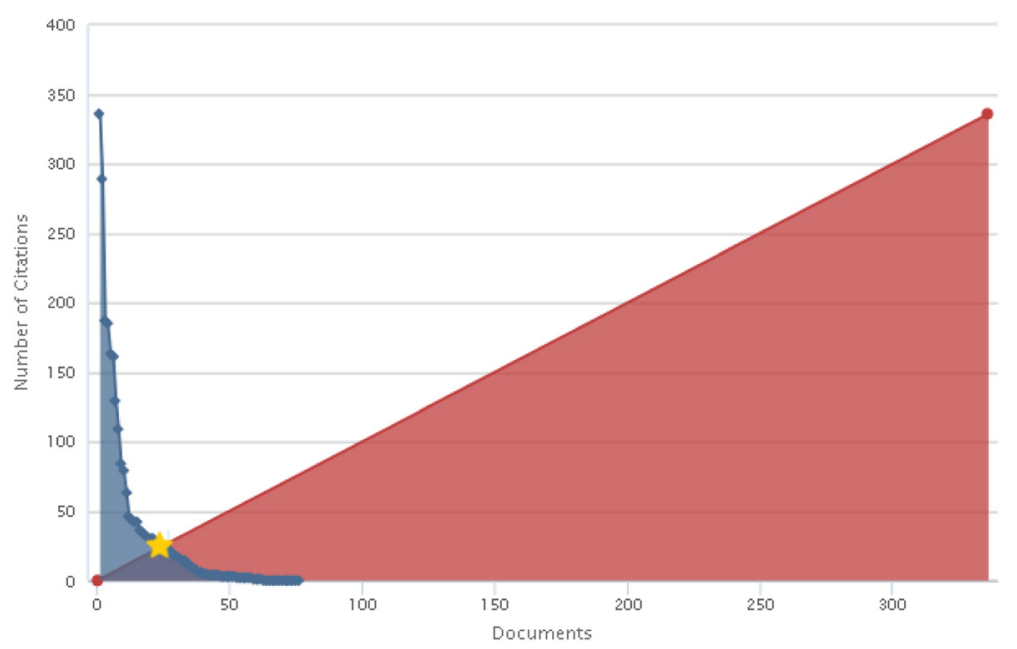

Fig. $3 \mathrm{H}$-graph of published documents in the studied field

highly cited papers which have the highest cited scientific publications. United Kingdom and India stand second rank.

In addition, we extracted sperately type of documents, type and number of highly cited study with name of the studied plant for each year (Table 2).

\section{Authors' name \& affiliation}

We found 40 authors as the first-author that published papers in the field of hypoglycemic antioxidative herbal medicine and diabetic nephropathy. Table 3 shows the top 5 first-author that had the most of publications in the field. Among top 5 first-author, 4 authors were from

Table 1 Citations and characteristics of top 10 highly cited published documents in antioxidative herbal medicine and diabetic nephropathy

\begin{tabular}{|c|c|c|c|c|c|c|}
\hline Title & $\begin{array}{l}\text { No. times } \\
\text { cited }\end{array}$ & Year & $\begin{array}{l}\text { Document } \\
\text { type }\end{array}$ & Country & Journal (IF) & $\begin{array}{l}\text { Subject area of the } \\
\text { journal }\end{array}$ \\
\hline $\begin{array}{l}\text { Green tea and its polyphenolic catechins: } \\
\text { medicinal uses in cancer and noncancer } \\
\text { applications }\end{array}$ & 336 & 2006 & $\begin{array}{l}\text { Review } \\
\text { article }\end{array}$ & $\begin{array}{l}\text { The United } \\
\text { States }\end{array}$ & Life Sciences (2.702) & $\begin{array}{l}\text { Biochemistry, general } \\
\text { and molecular biology } \\
\text { (Medicine) }\end{array}$ \\
\hline Curcumin: getting back to the roots & 289 & 2005 & $\begin{array}{l}\text { Review } \\
\text { article }\end{array}$ & $\begin{array}{l}\text { The United } \\
\text { States }\end{array}$ & $\begin{array}{l}\text { Annals of the New York } \\
\text { Academy of Sciences } \\
(-\ldots)\end{array}$ & $\begin{array}{l}\text { Biochemistry, Genetics } \\
\text { and Molecular Biology }\end{array}$ \\
\hline $\begin{array}{l}\text { Beneficial effects of soy phytoestrogen intake in } \\
\text { postmenopausal women with type } 2 \text { diabetes }\end{array}$ & 187 & 2002 & $\begin{array}{l}\text { Original } \\
\text { article }\end{array}$ & $\begin{array}{l}\text { United } \\
\text { Kingdom }\end{array}$ & Diabetes Care (8.570) & Medicine \\
\hline Antidiabetic agents from medicinal plants & 185 & 2006 & $\begin{array}{l}\text { Review } \\
\text { article }\end{array}$ & South Korea & $\begin{array}{l}\text { Current Medicinal Chemistry } \\
(3.853)\end{array}$ & $\begin{array}{l}\text {-Molecular Medicine } \\
\text {-Pharmacology }\end{array}$ \\
\hline $\begin{array}{l}\text { Resveratrol improves insulin sensitivity, reduces } \\
\text { oxidative stress and activates the Akt pathway } \\
\text { in type } 2 \text { diabetic patients }\end{array}$ & 163 & 2011 & $\begin{array}{l}\text { Original } \\
\text { article }\end{array}$ & $\begin{array}{l}\text { The United } \\
\text { States }\end{array}$ & $\begin{array}{l}\text { British Journal of Nutrition } \\
(3.342)\end{array}$ & Medicine \\
\hline $\begin{array}{l}\text { Mexican plants with hypoglycaemic effect used } \\
\text { in the treatment of diabetes }\end{array}$ & 161 & 2005 & $\begin{array}{l}\text { Review } \\
\text { article }\end{array}$ & $\begin{array}{l}\text { United } \\
\text { Kingdom }\end{array}$ & $\begin{array}{l}\text { Journal of Ethnopharmacology } \\
\text { (2.998) }\end{array}$ & Pharmacology \\
\hline $\begin{array}{l}\text { Plant foods in the management of diabetes } \\
\text { mellitus: Spices as beneficial antidiabetic food } \\
\text { adjuncts }\end{array}$ & 129 & 2005 & $\begin{array}{l}\text { Review } \\
\text { article }\end{array}$ & India & $\begin{array}{l}\text { International Journal of Food } \\
\text { Sciences and Nutrition (1.206) }\end{array}$ & Food Science \\
\hline $\begin{array}{l}\text { Role of selected Indian plants in management } \\
\text { of type } 2 \text { diabetes: a review }\end{array}$ & 109 & 2004 & $\begin{array}{l}\text { Review } \\
\text { article }\end{array}$ & India & $\begin{array}{l}\text { Journal of Alternative and } \\
\text { Complementary Medicine } \\
(1.585)\end{array}$ & Medicine \\
\hline Ginseng and diabetes & 84 & 2005 & $\begin{array}{l}\text { Original } \\
\text { article }\end{array}$ & $\begin{array}{l}\text { The United } \\
\text { States }\end{array}$ & $\begin{array}{l}\text { American Journal of Chinese } \\
\text { Medicine (2.625) }\end{array}$ & Medicine \\
\hline $\begin{array}{l}\text { The role of antioxidant micronutrients in the } \\
\text { prevention of diabetic complications }\end{array}$ & 79 & 2004 & $\begin{array}{l}\text { Review } \\
\text { article }\end{array}$ & France & $\begin{array}{l}\text { Treatments in Endocrinology } \\
(--)\end{array}$ & $\begin{array}{l}\text { Biochemistry, Genetics } \\
\text { and Molecular Biology } \\
\text { (Endocrinology) }\end{array}$ \\
\hline
\end{tabular}


Table 2 Scientometry analysis of scientific productions on antioxidative hypoglycemic herbal medicines in diabetic nephropathy

\begin{tabular}{|c|c|c|c|c|c|c|c|}
\hline \multirow{2}{*}{$\begin{array}{l}\text { Publication } \\
\text { (yr) }\end{array}$} & \multirow{2}{*}{$\begin{array}{l}\text { Enrolled } \\
\text { studies }(n)\end{array}$} & \multicolumn{3}{|l|}{ Type of studies } & \multicolumn{3}{|c|}{ Highly cited study } \\
\hline & & Original article $(n)$ & Review article $(n)$ & Case report (n) & Type of study & Citation $(n)$ & Studied plant \\
\hline 2014 & 10 & 7 & 3 & - & Review article & 12 & Curcumin \\
\hline 2013 & 21 & 8 & 12 & 1 & Review article & 33 & Polyphenols \\
\hline 2012 & 8 & 3 & 4 & 1 & Review article & 44 & $\overline{\text { (natural products) }}$ \\
\hline 2011 & 7 & 5 & 2 & -— & Original article & 163 & Resveratrol \\
\hline 2010 & 5 & 3 & 2 & -—- & Original article & 30 & Satureja khuzestanica \\
\hline 2009 & 3 & 3 & -—— & -—- & Original article & 63 & Grape seed extract \\
\hline 2008 & 4 & 4 & -—- & -—- & Original article & 42 & Pycnogenol \\
\hline 2007 & 1 & -—- & 1 & - - & Review article & 10 & Flavonoid \\
\hline 2006 & 6 & 2 & 4 & -—— & Review article & 336 & Green tea \\
\hline 2005 & 8 & 2 & 6 & -—- & Review article & 289 & Curcumin \\
\hline 2004 & 4 & 1 & 3 & -— & Review article & 109 & Indian plants \\
\hline 2002 & 1 & 1 & -—- & - - & Original article & 187 & Phytoestrogen \\
\hline
\end{tabular}

Iran and one author was from Canada. Fallah Huseini, H." with 11 articles followed by "Larijani, B." with 6 papers had the highest number of publications in the studied field, and both of them were from Iran.

\section{Co-authorship mapping \& clustering}

Co-authorship mapping and clustering assessment is one of the factors to provide information on scientific collaboration between co-authors in the field by using VOSviewer software. It was considered 2 documents as the minimum number of published scientific papers by one author to map co-authorship. Out of 342 authors, 11 authors meet this threshold. Within them, 2 auhors were without co-authorship which excluded from analysis. Co-authorship network and density views are shown in Figs. 3 and 4, respectively. Top 5 authors in our studied field based on co-authorship are "Fallah Huseini, H." (16 co-authorship) followed by "Heshmat, R." (13 coauthorship), "Larijani, B." (11 co-authorship), "Kianbakht,
S." and "Jafariazar, Z." each one with 7 co-auhorships (Fig. 4). According to Fig. 5, the highest density in the network belonged to "Fallah Huseini, H.".

\section{Institutes'charastristics published documents}

Table 4 shows the institution wise collaborations of publications with its affiliations. The Tehran University of Medical Sciences (TUMS)" has stood its first place with 13 publications $(16.66 \%)$. The second place has been occupied by Iranian Academic Center for Education, Culture and Research (ACECR)" with 10 published papers (12.82\%).

In accordance with top 10 countries, all of 5 top institutions' relations were from Iran. Details of the findings are shown in Table 4.

\section{Charastristics of main journal (source)}

Table 5 shows the charastristics of main journals. The "Journal of Medicinal Plants" has scored the first rank with 7 publications. "Evidence Based Complementary

Table 3 Top 5 authors according to the highest number of published documents in our study

\begin{tabular}{|c|c|c|c|c|}
\hline Rank & Author name & $\begin{array}{l}\text { Documents } \\
\text { (number/percent) }\end{array}$ & Affiliation & Country \\
\hline 1 & $\begin{array}{l}\text { Fallah Huseini, } \\
\text { H./Huseini, H.F. }\end{array}$ & $11 / 14.10$ & $\begin{array}{l}\text { Iranian Academic Center for Education, Culture and Research, Department of } \\
\text { Pharmacology and Applied Medicine }\end{array}$ & Iran \\
\hline 2 & Larijani, B. & $6 / 7.69$ & Tehran University of Medical Sciences, Endocrinology and Metabolism Research Center & Iran \\
\hline 3 & Heshmat, R. & $5 / 6.41$ & Tehran University of Medical Sciences, Chronic Diseases Research Center & Iran \\
\hline 4 & Kianbakht, S. & $5 / 6.41$ & $\begin{array}{l}\text { Iranian Academic Center for Education, Culture and Research, Department of } \\
\text { Pharmacology and Applied Medicine }\end{array}$ & Iran \\
\hline 5 & Lee, T. & $2 / 2.56$ & Health Centre of Milton, Milton, ON & Canada \\
\hline
\end{tabular}




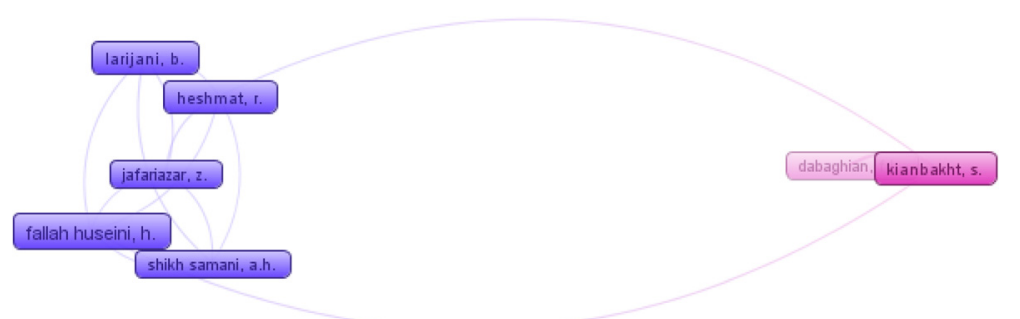

Fig. 4 Map of co-authorship network of the authors published scientific papers in the studied field

and Alternative Medicine" with 5 documents stood second rank. Other ranks were followed by "Phytotherapy Research" with 3 documents, and "Fitoterapia" and "Complementary Therapies in Medicine" each one with 2 documents.

Impact factor of all of 5 top journals, except for "Journal of Medicinal Plants" were remarkable (nearly 2). Within studied herbal medicine in these journals, the highest cited document was on Satureja khuzestanica. Details of the results are shown in Table 5.

\section{Discussion}

In the present study, 78 scientific products extraction was analyzed from Scopus database in field of antioxidative hypoglycemic plants and diabetic nephropathy.

Since, Scopus search engine is known as one of the largest abstract and citation database of peer-reviewed literature: scientific journals, books and conference proceedings [11-13], our study is given a reliable scientific visalization to researchers in published sholary literature performed in field of antioxidative hypoglycemic plants and diabetic nephropathy around the world.

Although, our findings showed an increasing trend in publishing the papers in studied field with a significant R-squared value of 0.459 , we found some temporary declines in years' 2006, 2007, 2009, and 2014. One reason of these reports may be related to negative effect of international sanction against Iran [16].
The majority of published products in the studied field were original articles (58\%). Due to WHO recommendation to encourage researchers for performing more scientific studies in field of herbal medicine and diabetes [17], we faced the increasing trend in the field of our study. In addition, when we assessed the subject area of the published documents, top subject area was medicine that followed by drug. As shown in Table 1, all of top 10 highly cited papers have published in international journals. There is a remarkable point here that these journals are not only scholarly valuable (IF $>2$ ), but also the subject area of them are medicine and/or pharmacology. As we said previously, IF can reflect the importance of the paper with its number [14]. On the other word, journals with high IF are journals with high ranking. The $h$-index and $h$-gragh of our documents are revealed these top 10 highly cited articles are the highest quality papers, and so would be mostly published in the high-impact journals and/or seen by more readers due to availability of older articles for longer periods compared to more recent published papers. Accordingly, all of above our results are in line worldwide medical professions' interest to discover new drugs that have more safety, less side effects and cost by focusing on natural products such as hypoglycemic antioxidative herbal medicines $[2,18]$.

After considering the citation report according to the article, the top document was entitled "Green tea and its polyphenolic catechins: medicinal uses in cancer and noncancer applications" that published in journal of

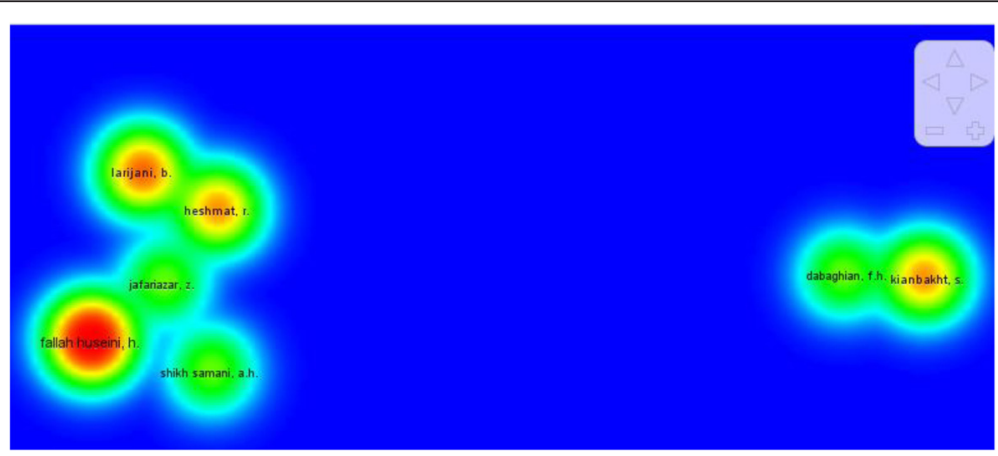

Fig. 5 Density view of co-authorship network of the authors published scientific papers in the studied field 
Table 4 Names and characteristics of top 5 institutes for the published documents in the studied filed

\begin{tabular}{llll}
\hline Rank & Institution name & $\begin{array}{l}\text { Documents } \\
\text { (number/percent) }\end{array}$ & Country \\
\hline 1 & $\begin{array}{l}\text { Tehran University of Medical } \\
\text { Sciences }\end{array}$ & Iran \\
2 & $\begin{array}{l}\text { Iranian Academic Center for } \\
\text { Education, Culture and Research }\end{array}$ & $10 / 12.82$ & Iran \\
3 & $\begin{array}{l}\text { Iranian Ministry of Health and } \\
\text { Medical Education }\end{array}$ & $4 / 5.13$ & Iran \\
4 & $\begin{array}{l}\text { Baqiyatallah Medical Sciences } \\
\text { University }\end{array}$ & $3 / 3.85$ & Iran \\
5 & Institute of Medicinal Plants Iran & $3 / 3.85$ & Iran \\
\hline
\end{tabular}

"Life Scinces" with IF of 2.702 and 336 citation number. It noted from Scopus analysis tools' report, this top document was a review article. The top 3 plant highly cited papers in plant in the present study were Green tea, Curcumin, and phytoestrogens. These studies were top 3 highly cited documents not only when analyzed total enrolled studies, but also when analyzed studies' results sperately for each year. This fact could confirm our findings that we faced with growing interest of the medical professions to WHO recommendation.

According to country distribution of scientic publications in our study, the majority of the papers were from Iran and the the United States ranked the second. Iran's 20 year national vision document was predicted the highest rank in science and technology for Iran compared to other developed country by 2025 [19]. Based on this, a high rate of published scholarly paper was expected from Iran. The first four authors of top 5 first-authors were Iranian which this fact was in line previous studies [20]. This fact was also approved by co-authorship mapping and clustering. In addition, when we assessed the institutional affiliation of the authors participated in publishing documents in the studied field, all of top 5 institutes were from Iran. "Tehran University of Medical Sciences" had the highest affiliation among institutes. On the other word, despite international sanction against Iran, the results of our study verified that Iran has a remarkable position in scientific productions in field of hypoglycemic antioxidative herbal medicine and diabetic nephropathy compared to other countries. The reason of this fact may be related to significantly increase in number of related multidisplinary faculties, research centers/institutes, related academic specialists, students, and research projects that all of them have been shown positive effects on number of published articles, and their citations [21].

Our study had some strengths as well as some limitations. Firstly, for the first time, this study focused on scientometric analysis of antioxidative hypoglycemic herbal medicine in diabetic nephropathy. Moreover, we used Scopus web database that has a high coverage in multidispline branches of science which can result in reliable analysis. The most limitation of this study was exclusion of scholarly literatures indexed outside of Scopus database that could be resulted in lose some highly cited scientific documents published in non-Scopus journals.

\section{Conclusions}

The study concluded that there is an increasing trend in producing of scientific papers in field of antioxidative hypoglycemic herbal medicines and diabetic nephropathy, along remarkable position for Iranian scientists in this field. However, despit a significant promising in scientific productivity in the studied field, number of publications are insufficient and we need more researches and scholary publications in this topic.

\section{Availability of data and materials}

As this study was a desk research which did not included any human subjects (neither human data nor human material), any ethical committee approval was needed. Moreover, for the same reason there was not necessary informed consent of the participants in the study. So, all of above three sections do not compatible.

Table 5 Characteristics of top 5 sources for the published documents in field of antioxidative traditional medicine and diabetic nephropathy

\begin{tabular}{llllll}
\hline Title of journal (IF) & $\begin{array}{l}\text { Documents } \\
\text { (number/percent) }\end{array}$ & $\begin{array}{l}\text { Total citations } \\
\text { to document }\end{array}$ & $\begin{array}{l}\text { Citation per } \\
\text { document }\end{array}$ & $\begin{array}{l}\text { Citation to highest } \\
\text { cited document }\end{array}$ & $\begin{array}{l}\text { Plant studied in highest cited } \\
\text { document }\end{array}$ \\
\hline $\begin{array}{l}\text { Journal of Medicinal } \\
\text { Plants (- }\end{array}$ & $7 / 8.97$ & 27 & 3.86 & 11 & Anti-diabetic medicinal plants \\
$\begin{array}{l}\text { Evidence Based Complementary } \\
\text { and Alternative Medicine (1.88) }\end{array}$ & $5 / 6.41$ & 41 & 8.2 & 30 & Satureja khuzestanica \\
$\begin{array}{l}\text { Phytotherapy Research (2.66) } \\
\text { Fitoterapia (2.216) }\end{array}$ & $3 / 3.85$ & 50 & 16.67 & 26 & Citrullus colocynthis (L.) \\
$\begin{array}{l}\text { Complementary Therapies in } \\
\text { Medicine (1.545) }\end{array}$ & $2 / 2.56$ & 39 & 19.5 & 21 & Brown algae \\
\hline
\end{tabular}




\section{Endnotes}

\section{There is not any endnotes in the manuscript.}

\section{Abbreviations}

DM: Diabetes mellitus; CKD: Chronic kidney disease; ADA: American Diabetes Association; MESH: Medical subject headings; IF: Impact factor; VOSviewer: Visualizing Scientific Landscapes; TUMS: Tehran University of Medical Sciences; ACECR: Academic Center for Education, Culture and Research.

\section{Competing interests}

The authors declare that they have no competing interests.

\section{Authours' contributions}

"OTM participated in the design of the study, collected data, analyzed data and wrote draft of the manuscript. RA collected data, analyzed data and helped to write draft of the manuscript. BL and MA equally contributed, conceived the study, participated in its design, and helped to collect data \& and draft the manuscript. All authors read and approved the final manuscript."

\section{Acknowledgements}

This article is extracted from PhD Thesis of Ozra Tabatabaei-Malazy, without any financial support.

\section{Funding}

This study is performed without any supporting fund.

\section{Author details}

${ }^{1}$ Diabetes Research Center, Endocrinology and Metabolism Clinical Sciences Institute, Tehran University of Medical Sciences, Tehran, Iran. ${ }^{2}$ Endocrinology and Metabolism Research Center, Endocrinology and Metabolism Clinical Sciences Institute, Tehran University of Medical Sciences, Tehran, Iran. ${ }^{3}$ EBM Group, Endocrinology and Metabolism Research Center, Endocrinology and Metabolism Clinical Sciences Institute, Tehran University of Medical Sciences, Tehran, Iran. ${ }^{4}$ Department of Toxicology and Pharmacology, Faculty of Pharmacy, and Pharmaceutical Sciences Research Center, Tehran University of Medical Sciences, Tehran, Iran.

\section{Received: 13 August 2015 Accepted: 6 February 2016}

\section{- 1. - . 10}

\section{References}

1. American Diabetes Association. Microvascular complications and foot care Sec.9. In standards of medical care in diabetes -2015. Diabetes Care. 2015; 38(Suppl1):S58-66. doi:10.2337/dc15-S012.

2. Tabatabaei-Malazy O, Larijani B, Abdollahi M. Targeting metabolic disorders by natural products. J Diabetes Metab Disord. 2015;14:57. doi:10.1186/s40200-015-0184-8.

3. Kelly JP, Kaufman DW, Kelley K, Rosenberg L, Anderson TE, Mitchell AA. Recent trends in use of herbal and other natural products. Arc Intern Med. 2005;165:281-6.

4. Marinac JS, Buchinger CL, Godfrey LA, Wooten JM, Sun C, Willsie SK. Herbal products and dietary supplements: a survey of use, attitudes, and knowledge among older adults. J Am Osteopath Assoc. 2007;107(1):13-20. quiz 21-23.

5. Falagas ME, Kouranos VD, Arencibia-Jorge R, Karagerorgopoulos DE. Comparison of SGImago journal rank indicator with journal impact factor. FASEB J. 2006;22:2623-8.

6. Jiang F, Zhang J, Wang $X$, Shen $X$. Important steps to improve translation from medical research to health policy. J Transl Med. 2013:11:33. doi:10.1186/1479-5876-11-33.

7. Scott JA, King GL. Oxidative stress and antioxidant treatment in diabetes. Ann N Y Acad Sci. 2004;1031:204-13.

8. Rahimi R, Nikfar S, Larijani B, Abdollahi M. A review on the role of antioxidants in the management of diabetes and its complications. Biomed Pharmacother. 2005;59:365-73.

9. Saeidnia S, Abdollahi M. Toxicological and pharmacological concerns on oxidative stress and related diseases. Toxicol Appl Pharmacol. 2013;273:442-55.

10. Tabatabaei-Malazy O, Nikfar S, Larijani B, Abdollahi M. Influence of ascorbic acid supplementation on type 2 diabetes mellitus in observational and randomized controlled trials; a systematic review with meta-analysis. J Pharm Pharm Sci. 2014;17(4):554-82.
11. Haustein S, Peters I, Bar-llan J, Priem J, Shema H, Terliesner J. Coverage and adoption of altmetrics sources in the bibliometric community. Scientometrics. 2014;101:1145-63.

12. Bar-llan J. Citations to the "Introduction to informetrics" indexed by WOS, Scopus and Google Scholar. Scientometrics. 2010;82:495-506.

13. Masic I, Milinovic K. On-line biomedical databases-the best source for quick search of the scientific information in the biomedicine. Acta Inform Med. 2012;20(2):72-84.

14. Garfield E. Evaluative measures for resource quality: beyond the impact factor. Scripta Medica. 2010;41:7-13.

15. Baldock C, Ma R, Orton CG. The $\mathrm{h}$ index is the best measure of a scientist's research productivity. Med Phys. 2009;36:1043. doi:10.1118/1.3089421.

16. Saeidnia S, Abdollahi M. Consequences of international sanctions on Iranian scientists and the basis of science. Hepat Mon. 2013;13(9):e14843. doi:10.5812/hepatmon.14843.eCollection2013.

17. Day C. Traditional plant treatments for diabetes mellitus: pharmaceutical foods. Br J Nutr. 1998;80:203-8.

18. Newman DJ, Cragg GM. Natural products as sources of new drugs over the 30 years from 1981 to 2010. J Nat Prod. 2012;75:311-35.

19. Larijani B, Majdzadeh R, Delavari A, Rajabi F, Khatibzadeh S, Esmailzadeh H, et al. Iran's health innovation and science development plan by 2025 . Iran J Public Health. 2009:38 Suppl 1:13-6.

20. Hasani-Ranjbar S, Zahedi HS, Abdollahi M, Larijani B. Trends in publication of evidence-based Traditional Iranian medicine in endocrinology and metabolic disorders. J Diabetes Metab Disord. 2013;12:49. doi:10.1186/2251-6581-12-49.

21. Djalalinia SH, Peykari N, Owlia P, Eftekhari MB, Habibi E, Falahat K, et al. The analysis of health research system evaluation in medical sciences universities. Iran J Public Health. 2013:42:60-5.

Submit your next manuscript to BioMed Central and we will help you at every step:

- We accept pre-submission inquiries

- Our selector tool helps you to find the most relevant journal

- We provide round the clock customer support

- Convenient online submission

- Thorough peer review

- Inclusion in PubMed and all major indexing services

- Maximum visibility for your research

Submit your manuscript at www.biomedcentral.com/submit
Biomed Central 